\title{
High blood pressure-lowering and vasoprotective effects of milk products in experimental hypertension
}

\author{
Pauliina I. Ehlers ${ }^{1 *}$, Anne S. Kivimäki ${ }^{1}$, Anu M. Turpeinen ${ }^{2}$, Riitta Korpela ${ }^{1}$ and Heikki Vapaatalo ${ }^{1}$ \\ ${ }^{1}$ Institute of Biomedicine, Pharmacology, University of Helsinki, PO Box 63, O0014 University of Helsinki, Finland \\ ${ }^{2}$ Valio Ltd, RED, PO Box 30, O0039 Valio, Finland \\ (Received 23 November 2010 - Revised 25 January 2011 - Accepted 7 March 2011 - First published online 10 May 2011)
}

\section{Abstract}

Milk casein-derived angiotensin-converting enzyme (ACE)-inhibitory tripeptides isoleucine-proline-proline (Ile-Pro-Pro) and valineproline-proline (Val-Pro-Pro) have been shown to have antihypertensive effects in human subjects and to attenuate the development of hypertension in experimental models. The aim of the present study was to investigate the effect of a fermented milk product containing Ile-Pro-Pro and Val-Pro-Pro and plant sterols on already established hypertension, endothelial dysfunction and aortic gene expression. Male spontaneously hypertensive rats (SHR) with baseline systolic blood pressure (SBP) of $195 \mathrm{mmHg}$ were given either active milk (tripeptides and plant sterols), milk or water ad libitum for 6 weeks. SBP was measured weekly by the tail-cuff method. The endothelial function of mesenteric arteries was investigated at the end of the study. Aortas were collected for DNA microarray study (Affymetrix Rat Gene 1.0 ST Array). The main finding was that active milk decreased SBP by 16 mmHg compared with water (178 (SEM 3 ) $v$. 195 (SEM 3) $\mathrm{mmHg} ; P<0 \cdot 001)$. Milk also had an antihypertensive effect. Active milk improved mesenteric artery endothelial dysfunction by NOdependent and endothelium-derived hyperpolarising factor-dependent mechanisms. Treatment with active milk caused mild changes in aortic gene expression; twenty-seven genes were up-regulated and eighty-two down-regulated. Using the criteria for fold change (fc) $<0.833$ or $>1.2$ and $P<0.05$, the most affected (down-regulated) signalling pathways were hedgehog, chemokine and leucocyte transendothelial migration pathways. ACE expression was also slightly decreased (fc $0 \cdot 86 ; P=0 \cdot 047$ ). In conclusion, long-term treatment with fermented milk enriched with tripeptides and plant sterols decreases SBP, improves endothelial dysfunction and affects signalling pathways related to inflammatory responses in SHR.

\section{Key words: Milk-derived bioactive peptides: Experimental hypertension: Spontaneously hypertensive rats: Plant sterols:} Endothelial function

Hypertension is one of the most important risk factors for CHD, heart failure, cerebrovascular disease and chronic kidney disease. The prevalence of hypertension is increasing worldwide, both in developed and developing countries ${ }^{(1)}$. Up to $30 \%$ of the world's adult population was estimated to have hypertension in $2000^{(2)}$. Any reductions in blood pressure, however small, are meaningful; a systolic blood pressure (SBP) reduction of $9 \mathrm{mmHg}$ and a diastolic blood pressure reduction of $5 \mathrm{mmHg}$ reduce the risk of stroke by $35-40 \%$ and CHD by $20-25 \%{ }^{(3)}$.

Besides pharmacological therapy, lifestyle and nutritional factors play a significant role in the prevention and treatment of hypertension and related disorders. Low saturated fat and $\mathrm{Na}$ intake and increased consumption of $\mathrm{K}$, Ca and soluble fibre positively affect blood pressure ${ }^{(4)}$. Plant sterols and stanols (also called as phytosterols and -stanols) have wellestablished cholesterol-lowering effects. The consumption of $2 \mathrm{~g}$ plant sterols per $\mathrm{d}$ has been shown to lower both total and LDL-cholesterol concentrations by approximately $10 \%$ in human subjects in different population groups ${ }^{(5,6)}$, but does not seem to decrease blood pressure as such in humans ${ }^{(7,8)}$. In addition, both epidemiological and intervention studies suggest that the consumption of low-fat dairy products is inversely related to the risk of hypertension ${ }^{(9-11)}$. The beneficial effect of milk on blood pressure is attributed to its high $\mathrm{Ca}$ and $\mathrm{K}$ content, and also to specific peptide sequences, which are cleaved from milk protein during gastrointestinal digestion, fermentation of milk with proteolytic starter cultures

Abbreviations: ACE, angiotensin-converting enzyme; ACh, acetylcholine; COX, cyclo-oxygenase; EDHF, endothelium-derived hyperpolarising factor; eNOS, endothelial NO synthase; fc, fold change; Ile-Pro-Pro, isoleucine-proline-proline; L-NAME, $N^{\mathrm{G}}$-nitro-L-arginine methyl ester; PE, phenylephrine; RAS, renin-angiotensin system; SBP, systolic blood pressure; SHR, spontaneously hypertensive rat; SNP, sodium nitroprusside; TRAM-34, 1-[(2-chlorophenyl)diphenylmethyl]-1H-pyrazole; Val-Pro-Pro, valine-proline-proline.

*Corresponding author: Dr Pauliina I. Ehlers, fax +358 191 25364, email pauliina.ehlers@helsinki.fi 
or by enzymic hydrolysis ${ }^{(12)}$. Milk products fermented with Lactobacillus belveticus contain casein-derived tripeptides isoleucine-proline-proline (Ile-Pro-Pro) and valine-prolineproline (Val-Pro-Pro), which have been shown to possess antihypertensive effects in human subjects ${ }^{(13,14)}$ and in experimental models of hypertension ${ }^{(15-19)}$.

The effect of tripeptides or fermented milk products containing them without or with plant sterols has been studied using young spontaneously hypertensive rats $(\mathrm{SHR})^{(16,17,20,21)}$, young high-salt-fed Goto-Kakizaki rats ${ }^{(18)}$ and double transgenic rats harbouring human renin and angiotensinogen genes $^{(19)}$. In these studies (duration 3-16 weeks), the longterm intake of tripeptides has been found to attenuate the SBP increase of the rats by 8 to $21 \mathrm{mmHg}$ depending on the study, strain and milk product. Older SHR with established hypertension have been used only in studies investigating the acute effect of tripeptides on blood pressure ${ }^{(15,22)}$. Accordingly, there are no published data on the possible long-term antihypertensive effects of tripeptides Ile-Pro-Pro and Val-Pro-Pro in rats that already have established hypertension.

Blood vessels contribute to blood pressure regulation by controlling vascular resistance. Due to ageing, increased blood pressure or other pathophysiological factors, arteries stiffen and gradually lose their ability to adjust to blood pressure changes ${ }^{(23)}$. Endothelial dysfunction is often observed in the presence of CVD and risk factors, such as hypertension ${ }^{(24)}$. Impaired endothelium-dependent relaxation, a measure of endothelial dysfunction, is observed in various experimental models of hypertension, such as $\mathrm{SHR}^{(25-27)}$, angiotensin IIinduced hypertension ${ }^{(28,29)}$, double transgenic rats ${ }^{(30)}$ and salt-loaded type 2 diabetic Goto-Kakizaki rats ${ }^{(18,31)}$. Besides the beneficial effects on blood pressure, tripeptides or fermented milk products containing them have shown to have vasoprotective effects on the endothelial function of rat arteries in some previous studies ${ }^{(18,32)}$.

The mechanisms behind the effects of tripeptides IlePro-Pro and Val-Pro-Pro on blood pressure and vascular function have been at least partly related to the renin-angiotensin system (RAS) and, more precisely, to angiotensin-converting enzyme (ACE) inhibition ${ }^{(18,33,34)}$. However, the clinical studies in particular have not been able to consistently prove this ${ }^{(35-37)}$. Thus, to obtain more insight into the mechanistic questions, we applied DNA microarray technology to detect the possible changes in aortic gene expression after longterm treatment with a tripeptide-containing milk product.

Based on the above-mentioned findings, our hypothesis was that long-term treatment with a fermented milk product containing ACE-inhibitory tripeptides and plant sterols could lower already increased blood pressure and improve endothelial function in SHR with established hypertension. We hypothesised that tripeptides and plant sterols combined could offer additional benefit to the treatment of experimental hypertension. We also hypothesised that alterations in the expression of the genes related to the RAS and vascular inflammation could be observed in the rat aorta and could explain the known beneficial cardiovascular effects of the tripeptide-containing milk products.

\section{Methods}

\section{Experimental protocol}

The protocol was approved by the National Animal Experimentation Committee according to EC Directive 86/609/EEC and the Finnish Experimental Animal Act 62/2006. A total of twelve male SHR were obtained from Charles River Laboratories (Sulzfeld, Germany) at the age of 14 weeks. The rats were housed three to a cage in a standard experimental animal laboratory (illuminated from 07.00 to 19.00 hours; temperature $22 \pm 2^{\circ} \mathrm{C}$; humidity $55 \pm 15 \%$ ). The rats had free access to standard rat pellets (2018 Teklad Global 18\% Protein Rodent Diet; Harlan Laboratories, Madison, WI, USA) and water.

After 1 week of adaptation, baseline blood pressure measurements were performed. The systolic blood pressure (SBP) of the rats was assessed by the tail-cuff method using an Apollo 2AB Blood Pressure Analyzer (model 179-2AB; IITC Life Science, Woodland Hills, CA, USA). Rats were placed in restrainer tubes and warmed in a heated chamber $\left(32-34^{\circ} \mathrm{C}\right)$ for $15-20 \mathrm{~min}$ to make the pulsations of the tail artery detectable. After obtaining three consecutive and successful recordings without disturbance of the signal, the average of the values was regarded as the SBP. Thereafter, 15 -week-old rats were randomised into two groups (six animals per group) based on SBP values and body weights to receive either: (1) a milk product ('milk') or (2) a milk product containing tripeptides $(18 \mathrm{mg} / \mathrm{l})$ and plant sterols $(0 \cdot 8 \mathrm{~g} / 100 \mathrm{~g})$ ('active milk') (for details, see below) as the drinking fluid ad libitum for 6 weeks. Drinking bottles were changed and fluid consumption was monitored daily. Feed consumption was monitored weekly.

During the experiment, the SBP of the rats was measured every week at the same time of day by the same researcher and in random order. To confirm that the stable phase of hypertension was reached, a similar experimental protocol was performed with age-matched SHR ( $n$ 6), which received only water as the drinking fluid.

\section{Study products}

Study products were provided by Valio Ltd (Helsinki, Finland). The active milk was a yogurt-like milk product, which was fermented by L. helveticus and to which proline-specific endoprotease (DSM, Heerlen, Netherlands), standardised peptide powder and a plant sterol mixture were added during preparation. The plant sterol mixture (Cognis, Monheim, Germany) was obtained by esterification of non-esterified plant sterols with fatty acids obtained from vegetable oil $(5 \cdot 1 \mathrm{~g}$ SFA, $7.6 \mathrm{~g}$ MUFA and $27 \cdot 3 \mathrm{~g}$ PUFA per $100 \mathrm{~g}$ ), and contained mainly $\beta$-sitosterol (69\%), campesterol (15\%), $\beta$-sitostanol (8\%) and brassicasterol $(3 \%)$. The concentration of tripeptides in the active milk is determined by the manufacturing process. Only minor fluctuations in different batches are observed. The amount of plant sterols added to the product was based on our previous studies ${ }^{(17,18)}$ and the generally recommended dose of plant sterols for human use for lowering high LDLcholesterol (portion size of $250 \mathrm{~g}$ giving $2 \mathrm{~g}$ plant sterols) ${ }^{(38)}$. 
'Milk' was a fermented milk product containing neither tripeptides nor plant sterols in detectable amounts.

Both products were sweetened by sucrose $(8 \%, \mathrm{w} / \mathrm{w})$ and were low-fat $(<1 \%)$ and low-lactose $(<1 \%)$ containing $222 \mathrm{~kJ} / 100 \mathrm{~g}$ (milk) and $272 \mathrm{~kJ} / 100 \mathrm{~g}$ (active milk) energy.

The contents of energy nutrients, minerals, tripeptides Ile-Pro-Pro, Val-Pro-Pro and Leu-Pro-Pro and plant sterols were analysed by Valio Ltd, R\&D (Helsinki, Finland). Tripeptides were analysed with the Waters Aquity UPLC-Micromass ZQ2000 Mass Spectrometry System (Waters, Milford, MA, USA) and total plant sterol content by the method of Laakso ${ }^{(39)}$ with minor modifications as described by Jäkälä et al. ${ }^{(18)}$.

\section{Collection of the samples}

After a 6-week treatment period, rats were rendered unconscious with $\mathrm{CO}_{2}-\mathrm{O}_{2}$ (30:70; AGA, Riihimäki, Finland) and decapitated. The hearts, left kidneys and adrenal glands were excised, washed with ice-cold saline, blotted dry and weighed. The left ventricle was separated and weighed. Aortas were excised, placed in a sterile saline solution and cleaned of adherent connective tissue. Sections of $1 \mathrm{~cm}$ were cut, stored in RNA Stabilization Reagent (RNAlater; Qiagen, Helsinki, Finland) and maintained at $4^{\circ} \mathrm{C}$ for $24 \mathrm{~h}$, and then stored at $-20^{\circ} \mathrm{C}$. Superior mesenteric arteries were excised and placed in ice-cold oxygenated Krebs buffer ( $\mathrm{pH} 7 \cdot 4-7 \cdot 6$, composition in mmol/l: NaCl, 119.0; $\mathrm{NaHCO}_{3}, 25 \cdot 0$; glucose, $\left.11 \cdot 1 ; \mathrm{CaCl}_{2}, 1 \cdot 6 ; \mathrm{KCl}, 4 \cdot 7 ; \mathrm{KH}_{2} \mathrm{PO}_{4}, 1 \cdot 2 ; \mathrm{MgSO}_{4}, 1 \cdot 2\right)$ for vascular reactivity studies.

\section{Vascular reactivity measurements}

Mesenteric arteries were carefully cleaned of adherent connective tissue. Then a $5 \mathrm{~mm}$ section from the proximal end of the mesenteric artery-aorta junction was cut off and the following $3 \mathrm{~mm}$ section was used in the experiments. The endotheliumintact rings (one from each rat) were placed between stainlesssteel hooks (diameter $0.15 \mathrm{~mm}$ ) and mounted in a standard organ bath chamber (volume $10 \mathrm{ml}$ ) in Krebs solution (composition, as above, $37^{\circ} \mathrm{C}$ ), and oxygenated with $\mathrm{O}_{2}-\mathrm{CO}_{2}$ (95:5; AGA). The rings were initially equilibrated for $1 \mathrm{~h}$ with a resting tension of $1.0 \mathrm{~g}$. The force of contraction was measured with an isometric force-displacement transducer (EMKA Technologies, Paris, France).

The vascular reactivity of the mesenteric arteries was measured by adding vasoactive agents directly into the chambers either cumulatively (acetylcholine (ACh), sodium nitroprusside (SNP)) or as a single dose (phenylephrine $(\mathrm{PE}), \mathrm{KCl})$. The concentrations henceforth are the final concentrations in the organ chamber. The rings were equilibrated for 20-30 min between different experiments and washed two or three times with Krebs solution.

After the initial equilibration period, arterial rings were exposed to a high- $\mathrm{K}^{+}$-containing Krebs solution (60 mm) until reproducible contractile responses were obtained. The high- $\mathrm{K}^{+}$solution was prepared by equimolar substitution of $\mathrm{NaCl}$ by $\mathrm{KCl}$. Thereafter, arteries were pre-contracted with
$1 \mu \mathrm{M}-\mathrm{PE}$, and the relaxation to $1 \mu \mathrm{M}-\mathrm{ACh}$ was determined to check the presence of functional endothelium.

Endothelium-dependent relaxation of the mesenteric arteries was studied by pre-contracting the arterial rings with $1 \mu \mathrm{M}-\mathrm{PE}$ and constructing a concentration-response curve to ACh $(1 \mathrm{~nm}-10 \mu \mathrm{M})$ in the absence of inhibitors and in the presence of: (1) cyclo-oxygenase (COX) inhibitor diclofenac $(3 \mu \mathrm{M})$; (2) diclofenac and NO synthase (NOS) inhibitor $N^{\mathrm{G}}$-nitro-L-arginine methyl ester (L-NAME) (100 $\left.\mu \mathrm{M}\right)$; and (3) diclofenac, L-NAME, apamin $(0 \cdot 1 \mu \mathrm{M})$ and 1-[(2-chlorophenyl)diphenylmethyl]-1H-pyrazole (TRAM-34) (1 $\mu \mathrm{M})$, inhibitors of small- and intermediate-conductance Ca-activated $\mathrm{K}$ channels, $\mathrm{SK}_{\mathrm{Ca}}$ and $\mathrm{IK}_{\mathrm{Ca}}$, respectively. Arterial rings were exposed to different inhibitors $20 \mathrm{~min}$ before the PE pre-contraction.

Endothelium-independent relaxation of the mesenteric arteries was assessed by pre-contracting the arteries with $1 \mu \mathrm{M}-\mathrm{PE}$ and constructing a concentration-response curve to SNP $(1 \mathrm{~nm}-10 \mu \mathrm{m})$.

ACh- and SNP-induced relaxations are calculated as the percentage of PE-induced ( $1 \mu \mathrm{m})$ pre-contraction. The vascular contractile responses are expressed in grams.

\section{Compounds}

Acetylcholine chloride, diclofenac sodium salt, L-NAME, $(R)-(-)$-phenylephrine hydrochloride, SNP and TRAM-34 were purchased from Sigma-Aldrich (St Louis, MO, USA). Apamin was from Latoxan (Valence, France). Apamin and diclofenac were dissolved in distilled water and TRAM-34 in dimethyl sulfoxide, while all the other compounds were dissolved in Krebs solution.

\section{Statistical analysis}

All data are presented as mean values with their standard errors. Statistical analysis (except for microarray data) was performed using GraphPad Prism ${ }^{\circledR}$ software (version 4.02; GraphPad Software, Inc., La Jolla, CA, USA). One-way ANOVA followed by Bonferroni's multiple-comparison test were used to compare groups. When the data consisted of repeated observations at successive drug concentrations, ANOVA for repeated measurements was applied in order to investigate between-group differences. Differences were considered significant when $P<0 \cdot 05$.

\section{RNA isolation, CDNA preparation and hybridisation}

The GeneChip ${ }^{\circledR}$ Rat Gene 1.0 ST Array (Affymetrix, Santa Clara, CA, USA) was applied to produce DNA microarray gene chips from aortic samples of studied rats ( $n 3$ per group). Frozen aortic samples were homogenised and total RNA was prepared by TRIzol $^{\circledR}$ (Invitrogen, Carlsbad, CA, USA) and purified using an RNeasy Mini Kit (Qiagen). Total RNA was measured by a NanoDrop ${ }^{\circledR}$ Spectrophotometer (NanoDrop Technologies Inc., Wilmington, DE, USA) and sample quality was assessed by an Agilent 2100 Bioanalyzer (Agilent Technologies Inc., Santa Clara, CA, USA). A quantity of $100 \mathrm{ng}$ of total RNA was used to generate single-stranded 
Table 1. Daily intake of feed, drinking fluid, tripeptides, plant sterols and minerals in spontaneously hypertensive rats after 6 weeks of treatment with milk or active milk (containing tripeptides and plant sterols) $\dagger$ (Mean values with their standard errors)

\begin{tabular}{|c|c|c|c|c|c|c|}
\hline \multirow[t]{2}{*}{ Group. .. } & \multicolumn{2}{|c|}{ Water } & \multicolumn{2}{|c|}{ Milk } & \multicolumn{2}{|c|}{ Active milk } \\
\hline & Mean & SEM & Mean & SEM & Mean & SEM \\
\hline Feed $(\mathrm{g})$ & $18 \cdot 2$ & 0.7 & $9 \cdot 5^{\star \star \star}$ & 0.7 & $9 \cdot 9^{* \star *}$ & 0.3 \\
\hline Drinking fluid (g) & 8.4 & 0.1 & $91 \cdot 3^{\star \star *}$ & $5 \cdot 7$ & $83 \cdot 6^{\star \star \star}$ & 2.9 \\
\hline Tripeptides (mg/kg) & - & & 0.0 & 0 & 4.1 & 0.1 \\
\hline Plant sterols $(\mathrm{g} / \mathrm{kg})$ & _- & & 0.0 & 0 & 1.9 & 0.1 \\
\hline $\mathrm{Ca}(\mathrm{mg})$ & 182 & 7 & $217^{\star}$ & 9 & $208^{*}$ & 6 \\
\hline $\mathrm{Mg}(\mathrm{mg})$ & 36 & 1 & 31 & 2 & 31 & 1 \\
\hline $\mathrm{K}(\mathrm{mg})$ & 124 & 5 & $229^{\star *}$ & 12 & $209^{\star \star}$ & 9 \\
\hline $\mathrm{Na}(\mathrm{mg})$ & 42 & 2 & $67^{\star \star}$ & 3 & $58^{\star *}$ & 2 \\
\hline
\end{tabular}

Mean value was significantly different from that of the group that received water: ${ }^{\star} P<0.05,{ }^{\star \star} P<0.01,{ }^{\star \star \star} P<0.001$.

†All variables except plant sterols and tripeptides are presented as $\mathrm{mg}$ or $\mathrm{g}$ per rat per $\mathrm{d}$. Intakes of tripeptides and plant sterols are calculated as $\mathrm{mg}$ or $\mathrm{g}$ per $\mathrm{kg}$ body weight per $\mathrm{d}$. Mineral intakes are presented as feed + drinking fluid in total.

cDNA by the Ambion ${ }^{\circledR}$ WT Expression Kit (Applied Biosystems, Austin, TX, USA). Thereafter, the Gene Chip WT Terminal Labeling Kit (Affymetrix) was used for sample fragmentation, labelling and hybridisation for cartridge arrays. Arrays were washed, stained and scanned according to the manufacturer's instructions on the GeneChip ${ }^{\circledR}$ Rat Gene 1.0 ST Array (Affymetrix) covering over 27000 genes.

\section{Microarray data analysis}

The data analysis was done using Anduril ${ }^{(40)}$. Data were normalised with the robust multichip average (RMA) method ${ }^{(41)}$. The median value of three sample replicates was used to calculate differentially expressed genes. $P$ values were produced by two-sided Student's $t$ tests. $P$ values were corrected for multiple hypotheses by the false discovery rate method ${ }^{(42)}$. Pathway analysis was performed using signalling pathway impact analysis, which combines enrichment and pathway perturbation analysis ${ }^{(43)}$. Enrichment analysis counts the amount of differentially expressed genes in a given pathway. Perturbation analysis captures the topology of the pathway and the position of the gene in that pathway. Differentially expressed genes, where the fold change (fc) was $<0.833$ or $>1.2$ and $P<0.05$, were included in the signalling pathway impact analysis.

\section{Results}

\section{Intake of tripeptides, plant sterols and minerals}

At the beginning of the experiment, rats in the milk, active milk and water groups weighed 321 (SEM 3), 326 (SEM 5) and 305 (SEM 5) g on average, respectively. The weight gain of the rats during the study was 47 (SEM 4), 41 (SEM 2) and 39 (SEM 7) $\mathrm{g}$ in the milk, active milk and water groups, respectively (NS).

Daily intakes of feed, drinking fluid, tripeptides, plant sterols and minerals are presented in Table 1. Rats in the water group ingested significantly more feed and consumed significantly less drinking fluid than the rats in the milk and active milk groups. Also $\mathrm{Ca}, \mathrm{K}$ and $\mathrm{Na}$ intakes were significantly lower in the water group compared with the other groups. However, there were no statistically significant differences between the milk and active milk groups in any of these parameters besides tripeptide and plant sterol intake (Table 1).

\section{Blood pressure}

Long-term treatment ( 6 weeks) either with milk or active milk decreased the SBP of the SHR (Fig. 1). The decrease was statistically significant after 2 weeks of treatment $(P<0 \cdot 001 ;$ milk and active milk $v$. water). Although both the milk and active milk decreased SBP, the decline was stronger with the active milk, which contained tripeptides and plant sterols $(P<0.05)$. An upward trend back towards the baseline SBP values was seen in the milk group. At the end of the experiment, SBP was $16 \mathrm{mmHg}$ lower in the active milk group compared with the water group.

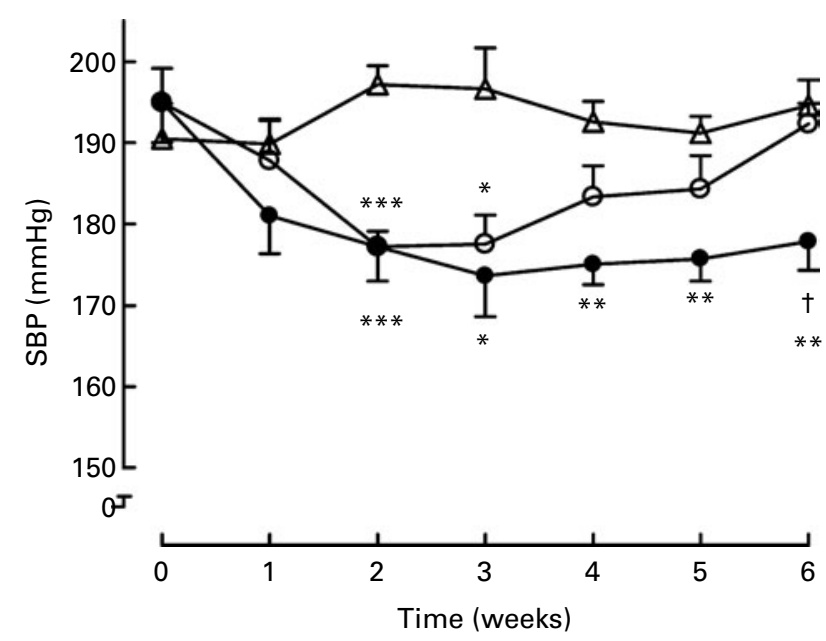

Fig. 1. Systolic blood pressure (SBP) during the 6-week treatment with milk $(\bigcirc)$, active milk $(\bullet)$ or water $(\triangle)$. Values are means ( $n 6$ per group), with standard errors represented by vertical bars. Mean value was significantly different from that of the group that received water: ${ }^{*} P<0.05,{ }^{* *} P<0.01$, ${ }^{\star * \star} P<0.001$. † Mean value was significantly different from that of the group that received milk $(P<0.05)$. 

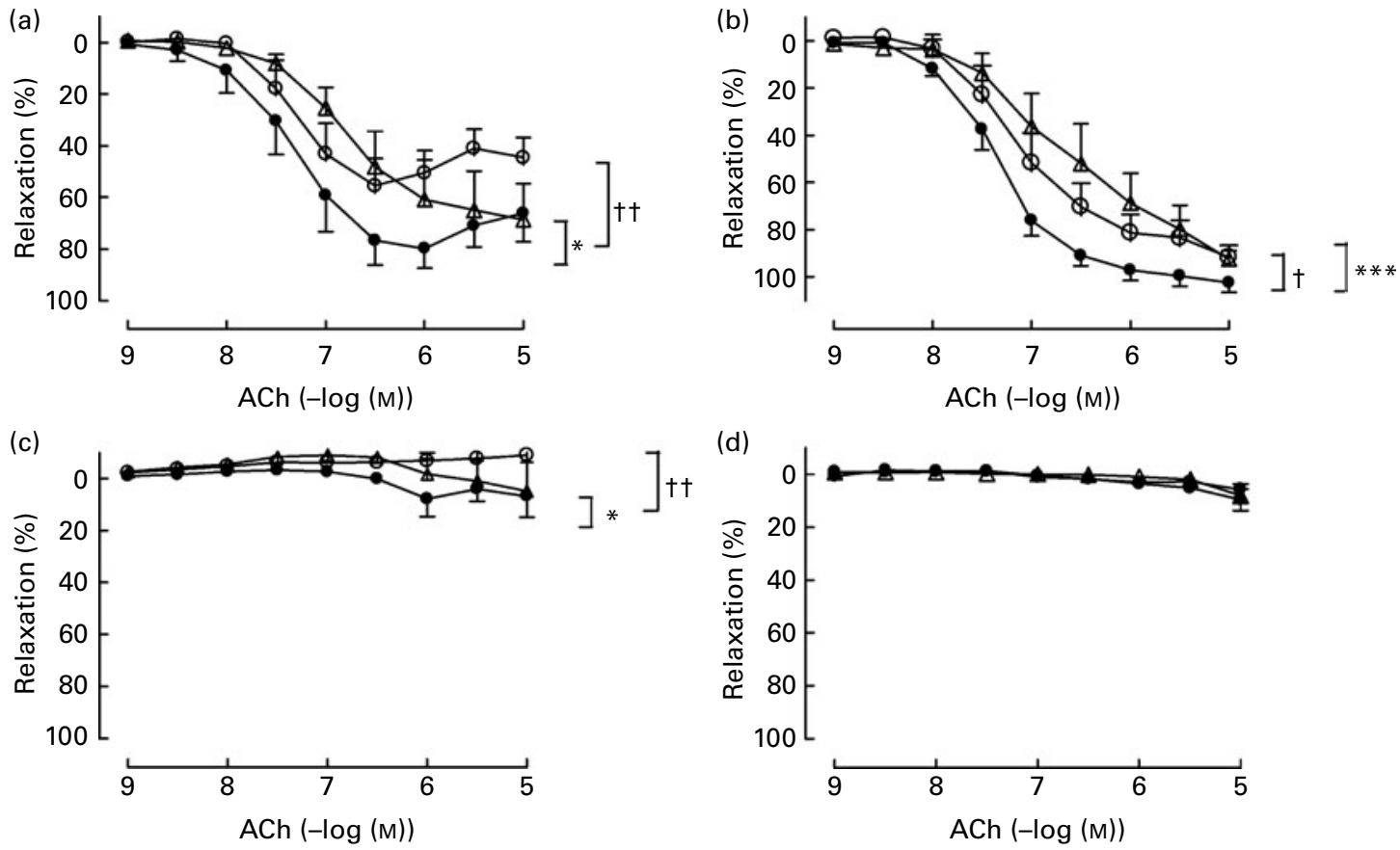

Fig. 2. Acetylcholine (ACh)-induced endothelium-dependent relaxations of spontaneously hypertensive rat mesenteric arteries treated with milk $(\bigcirc)$, active milk $(\bullet)$ or water $(\Delta)$ for 6 weeks. Values are means ( $n 5-6$ per group), with standard errors represented by vertical bars. (a) Relaxation without inhibitors. ${ }^{*}<0.05$ active milk $v$. water; $\dagger \dagger P<0.01$ active milk $v$. milk. (b) Relaxation after 20 min pre-incubation with diclofenac $(3 \mu \mathrm{M})$. ${ }^{\star \star \star} P<0.001$ active milk $v$. water; $\dagger P<0.05$ active milk $v$. milk. (c) Relaxation after $20 \mathrm{~min}$ pre-incubation with $N^{G}$-nitro-L-arginine methyl ester (L-NAME) (100 $\left.\mu \mathrm{M}\right)$ and diclofenac. ${ }^{\star} P<0.05$ active milk $V$. water; $\dagger \dagger P<0.01$ active milk $v$. milk. (d) Relaxation after 20 min pre-incubation with diclofenac, L-NAME, apamin (0.1 $\mu \mathrm{M})$ and 1-[(2-chlorophenyl)diphenylmethyl]$1 H$-pyrazole (TRAM-34) $(1 \mu \mathrm{M})$. There were no significant differences.

The heart rate of the rats was unaffected by the 6-week treatment with the milk or active milk compared with the water group (data not shown).

\section{Vascular tone}

The endothelial function of the mesenteric arteries, assessed by ACh-induced endothelium-dependent relaxation, was impaired in all SHR (Fig. 2(a)). However, treatment with active milk partly normalised this. The mesenteric arteries of rats treated with active milk for 6 weeks showed significantly better relaxation to ACh compared with the milk and water groups $(P<0.01$ and $P<0.05$, respectively). COX inhibition with diclofenac improved the ACh-induced relaxation in all groups; however, the active milk group was still superior to the other groups $(P<0.05$, active milk $v$. milk; $P<0.001$, active milk $v$, water) (Fig. 2(b)). NOS inhibition with L-NAME along with COX inhibition greatly attenuated the ACh-induced responses, demonstrating that relaxation was mediated mainly via $\mathrm{NO}$, with endothelium-derived hyperpolarising factor (EDHF) playing only a minor role (Fig. 2(c)). However, the mesenteric arteries of rats from the active milk group still showed some relaxation whereas the response was almost abolished in the other groups, suggesting that the active milk treatment was associated with amelioration in EDHF-dependent responses $(P<0 \cdot 05$, active milk $v$. water; $P<0 \cdot 01$, active milk $v$. milk). Finally, apamin and TRAM-34, inhibitors of small- and intermediateconductance Ca-activated $\mathrm{K}$ channels $\mathrm{SK}_{\mathrm{Ca}}$ and $\mathrm{IK}_{\mathrm{Ca}}$, totally abolished the relaxation in all groups (Fig. 2(d)).
SNP-induced endothelium-independent relaxation reached $100 \%$ in all groups (Fig. 3). The mesenteric arteries of rats from the water group had decreased sensitivity to SNP compared with those of the rats in the active milk group $(P<0.05)$. The difference between the milk and water groups was not statistically significant (NS).

PE- or KCl-induced contractile responses did not differ between the groups (data not shown).

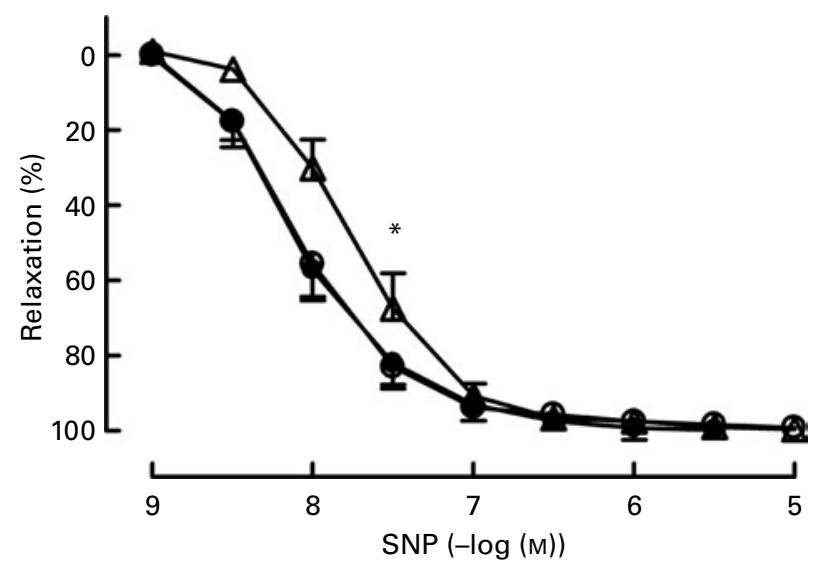

Fig. 3. Sodium nitroprusside (SNP)-induced endothelium-independent relaxations of spontaneously hypertensive rat mesenteric arteries treated with milk $(\bigcirc)$, active milk $(\bullet)$ or water $(\Delta)$ for 6 weeks. Values are means ( $n 6$ per group), with standard errors represented by vertical bars. ${ }^{\star} P<0.05$ active milk $v$. water. 


\section{Gene expression}

To investigate whether the 6-week intake of tripeptides and plant sterols changed the gene expression in SHR aorta, DNA microarray data from the rats that received either milk or active milk (containing tripeptides and plant sterols) were compared. In total, twenty-seven genes were up-regulated and eighty-two down-regulated. To obtain more information about the mechanisms behind the antihypertensive and vasoprotective effects of tripeptides, changes in the expressions of genes linked to the RAS, vascular function and inflammation were first analysed and are presented in Table 2. Although changes in the gene expressions were small, ACE and IL-13 receptor were less expressed in the active milk group (fc 0.86, $P=0.047$ and fc $0.71, P=0.0314$, respectively). Other genes filling the $\mathrm{fc}_{\mathrm{c}}$ criteria ( $\mathrm{fc}<0.833$ or $>1.2)$ but not reaching statistical significance $(P<0.05)$

Table 2. Changes in selected genes linked to the renin-angiotensin system, vascular function and inflammation detected in the aorta of spontaneously hypertensive rats after 6 weeks of treatment with milk or active milk (containing tripeptides and plant sterols)

\begin{tabular}{|c|c|c|c|}
\hline Description of the gene & Fold change* $^{*}$ & $P$ (if significant) $\dagger$ & $\begin{array}{c}\text { Fold change } \\
<0.833 \text { or }>1.2\end{array}$ \\
\hline \multicolumn{4}{|l|}{ Renin-angiotensin system } \\
\hline Angiotensin I-converting enzyme (ACE) & $0 \cdot 86$ & 0.047 & \\
\hline Angiotensin I-converting enzyme 2 (ACE2) & 1.04 & & \\
\hline Angiotensin II type $1 \mathrm{~A}$ receptor & 0.82 & & $X$ \\
\hline Angiotensin II type 1B receptor & 1.06 & & \\
\hline Angiotensin II type 2 receptor & nd & & \\
\hline Bradykinin receptor 1 (BK1) & 0.98 & & \\
\hline Bradykinin receptor 2 (BK2) & 0.89 & & \\
\hline Cathepsin G & 0.99 & & \\
\hline Chymase (mast cell protease 1) & 0.82 & & $\mathrm{X}$ \\
\hline Neutral endopeptidase (NEP) & 0.95 & & \\
\hline Prolyl endopeptidase (PEP) & 1.00 & & \\
\hline Proto-oncogene Mas & 0.99 & & \\
\hline Renin/prorenin receptor & $1 \cdot 12$ & & \\
\hline \multicolumn{4}{|l|}{ Vascular function } \\
\hline Arginase 1 & $1 \cdot 02$ & & \\
\hline Arginase 2 & 1.08 & & \\
\hline Connexin-37 & 0.88 & & \\
\hline Connexin-40 & 0.82 & & $\mathrm{X}$ \\
\hline Connexin-43 & $1 \cdot 11$ & & \\
\hline Endothelial nitric oxide synthase (eNOS) & 0.65 & & $\mathrm{X}$ \\
\hline Neuronal nitric oxide synthase (nNOS) & 0.84 & & \\
\hline Inducible nitric oxide synthase (iNOS) & 1.02 & & \\
\hline Endothelin-converting enzyme 1 (ECE-1) & 0.81 & & \\
\hline Endothelin-converting enzyme 2 (ECE-2) & 1.02 & & \\
\hline Endothelin-1 receptor $\left(\mathrm{ET}_{\mathrm{A}}\right)$ & 1.02 & & \\
\hline Endothelin-1 (ET-1) & 0.50 & & $\mathrm{X}$ \\
\hline Intercellular adhesion molecule 1 (ICAM-1) & 0.92 & & \\
\hline Muscarinic acetylcholine receptor M3 & 1.00 & & \\
\hline $\mathrm{IK}_{\mathrm{Ca}} 3 \cdot 1$ & 0.78 & & $X$ \\
\hline $\mathrm{SK}_{\mathrm{Ca}} 2 \cdot 2$ & 0.97 & & \\
\hline $\mathrm{SK}_{\mathrm{Ca}} 2 \cdot 3$ & $0 \cdot 88$ & & \\
\hline $\mathrm{BK}_{\mathrm{Ca}}$ subunit beta-1 & $1 \cdot 12$ & & \\
\hline $\mathrm{BK}_{\mathrm{Ca}}$ subunit beta-2 & $1 \cdot 00$ & & \\
\hline $\mathrm{BK}_{\mathrm{Ca}}$ subunit beta-4 & 0.94 & & \\
\hline Prostacyclin receptor & $1 \cdot 00$ & & \\
\hline Prostacyclin synthase & $1 \cdot 11$ & & \\
\hline Thromboxane A2 receptor (TP receptor) & $1 \cdot 12$ & & \\
\hline Thromboxane A synthase & 0.88 & & \\
\hline \multicolumn{4}{|l|}{ Inflammation } \\
\hline Cyclo-oxygenase-1 (COX-1) & $1 \cdot 15$ & & \\
\hline Cyclo-oxygenase-2 (COX-2) & 0.78 & & $\mathrm{X}$ \\
\hline Interleukin $1 b$ & 0.85 & & \\
\hline Interleukin 6 & 1.00 & & \\
\hline Interleukin $12 b$ & 1.08 & & \\
\hline Interleukin 13 receptor & 0.71 & 0.0314 & \\
\hline Nuclear factor NF-kappa-B subunit & 1.01 & & \\
\hline Prostaglandin E synthase & 1.02 & & \\
\hline EP1 receptor (prostaglandin E2 receptor subtype 1) & 1.00 & & \\
\hline EP3 receptor & 0.99 & & \\
\hline EP4 receptor & 0.87 & & \\
\hline Tumor necrosis factor alpha (TNF- $\alpha)$ & 1.00 & & \\
\hline
\end{tabular}

nd, Not detected.

${ }^{*}$ Fold change in the active milk group compared with the milk group; mean of three samples.

† Significant differences between the active milk and milk groups were evaluated by the two-sided Student's $t$ test. 
were angiotensin II type $1 \mathrm{~A}$ receptor (fc $0 \cdot 82$ ), chymase (fc $0 \cdot 82$ ), connexin-40 (fc 0.82 ), endothelial NO synthase (eNOS) (fc 0.65), endothelin-1 (fc 0.50), intermediate-conductance $\mathrm{K}$-activated Ca channel ( $\mathrm{IK}_{\mathrm{Ca}}$ ) (fc 0.78) and COX-2 (fc 0.78).

Thereafter, all differentially expressed genes (f $<0.833$ or $>1.2$ and $P<0.05)$ were subjected to pathway analysis. In total, twenty signalling pathways, presented in Table $3^{(44)}$, were changed in the active milk group compared with the milk group. The most changed pathways were the hedgehog signalling pathway, chemokine signalling pathway and the leucocyte transendothelial migration pathway.

\section{Organ weights}

Certain organs were dissected and weighed at the end of the experiment. Heart weight:body weight and left ventricle:body weight ratios were higher in the rats in the active milk group compared with the rats in the water group $(P<0 \cdot 01)$ (Table 4$)$. The rats in the milk group had higher adrenal gland weight compared with those in the water group $(P<0.05)$.

\section{Discussion}

The present study investigated the long-term effects of a fermented milk product containing tripeptides and plant sterols (active milk) on blood pressure, vascular tone and aortic gene expression in SHR with established hypertension. The main finding, not previously described, was that the longterm treatment with active milk decreases the SBP of SHR with established hypertension. In addition, endothelial function is significantly ameliorated by active milk involving both
NO- and EDHF-mediated mechanisms. Interestingly, milk without these active constituents also lowers blood pressure, although to a lesser degree.

In clinical studies, tripeptide-containing fermented milk products have been found to decrease SBP and diastolic blood pressure by approximately 5 and $2 \mathrm{mmHg}$, respectively, and the effect has been shown to be stronger in clearly hypertensive subjects than in subjects with mild hypertension ${ }^{(13,14)}$ Previous experimental studies have shown that long-term treatment of young SHR with tripeptide-containing milk products attenuates the development of hypertension ${ }^{(16,18,20,21,45)}$, and that SBP may be transiently lowered by 22 to $26 \mathrm{mmHg}$ by a single dosing of the tripeptides ${ }^{(15,22)}$. The present study demonstrated for the first time that established high blood pressure may be constantly lowered by a fermented milk product enriched with tripeptides and plant sterols as well; active milk decreased SBP by $16 \mathrm{mmHg}$ in SHR, which were aged 21 weeks at the end of the experiment.

In the present study, the active milk also contained plant sterols. Plant sterols and stanols effectively lower LDL-cholesterol, but do not seem to decrease blood pressure as such in human subjects ${ }^{(7,8)}$. Therefore, we do not assume that plant sterols contributed to the antihypertensive effect observed in the active milk group. In previous studies, plant sterols have rather increased than decreased blood pressure of rats ${ }^{(46)}$ When plant sterols and tripeptides have been combined together, the attenuating effect on the development of blood pressure has been less than with tripeptides alone ${ }^{(17)}$.

Milk, as such, also decreased blood pressure in the present study, although not to a similar degree as the active milk containing tripeptides and plant sterols. An inverse association

Table 3. Results for signalling pathway impact analysis (SPIA)

\begin{tabular}{|c|c|c|c|c|}
\hline KEGG name for the pathway ${ }^{(44)}$ & NDE & Gene(s) & Regulation & $\mathrm{pG}$ \\
\hline Hedgehog signaling pathway & 2 & Dhh (desert hedgehog) & Down & 0.0297 \\
\hline Chemokine signaling pathway & 3 & $\begin{array}{l}\text { Arrb1 (arrestin, beta 1) } \\
\text { Gng8 (G protein, gamma 8) }\end{array}$ & $\begin{array}{l}\text { Down } \\
\text { Down } \\
\text { Up }\end{array}$ & 0.0502 \\
\hline Leukocyte transendothelial migration & 2 & $\begin{array}{l}\text { Thy-1 (Thy-1 cell surface antigen) } \\
\text { Cldn-1 (claudin- } 1 \text { ) }\end{array}$ & $\begin{array}{l}\text { Down } \\
\text { Down }\end{array}$ & 0.0900 \\
\hline Complement and coagulation cascades & 1 & F3 (coagulation factor III) & Down & 0.2519 \\
\hline SNARE interactions in vesicular transport & 1 & Stx5 (syntaxin 5) & Up & 0.3454 \\
\hline TGF-beta signaling pathway & 1 & BMP-4/-6 & Down & 0.4344 \\
\hline Basal cell carcinoma & 1 & BMP-4/-6 & Down & 0.4398 \\
\hline NOD-like receptor signaling pathway & 1 & Pstpip1 (proline-serine-threonine phosphatase-interacting protein 1) & Down & 0.4669 \\
\hline PPAR signaling pathway & 1 & Scd1 (stearoyl-coenzyme A desaturase 1) & Down & 0.5342 \\
\hline B cell receptor signaling pathway & 1 & SHIP (SH2 domain containing inositol $5^{\prime}$-phosphatase) & Down & 0.5342 \\
\hline MAPK signaling pathway & 2 & $\begin{array}{l}\text { FInb (filamin, beta) } \\
\text { Arrb1 (arrestin, beta 1) }\end{array}$ & $\begin{array}{l}\text { Down } \\
\text { Down }\end{array}$ & 0.5363 \\
\hline Fc epsilon signaling pathway & 1 & SHIP (SH2 domain containing inositol 5'-phosphatase) & Down & 0.5597 \\
\hline Systemic lupus erythematosus & 1 & Hist1h4m (histone $\mathrm{H} 4)$ & Down & 0.5797 \\
\hline Fc gamma R-mediated phagocytosis & 1 & SHIP (SH2 domain containing inositol 5'-phosphatase) & Down & 0.5835 \\
\hline Tight junction & 1 & Cldn-1 (claudin-1) & Down & 0.6976 \\
\hline Parkinson's disease & 1 & UBIQ_RAT (ubiquitin) & Down & 0.7054 \\
\hline Insulin signaling pathway & 1 & SHIP (SH2 domain containing inositol $5^{\prime}$-phosphatase) & Down & 0.7153 \\
\hline JAK-STAT signaling pathway & 1 & II13ra2 (interleukin 13 receptor) & Down & 0.7177 \\
\hline Cytokine-cytokine receptor interaction & 1 & Cx3cr1 (chemokine receptor 1 ) & Down & 0.8186 \\
\hline Focal adhesion & 1 & Flnb (filamin, beta) & Down & 0.8258 \\
\hline
\end{tabular}

KEGG, Kyoto Encyclopedia of Genes and Genomes; NDE, number of differentially expressed genes on the pathway; pG, combination of pPERT (probability of observing a more intense perturbation than a perturbation factor by chance) and pNDE ( $P$ value to observe NDE number of genes on the pathway by chance). 
Table 4. Organ weight:body weight ratios $(\mathrm{g} / \mathrm{g} \times 1000)$

(Mean values with their standard errors)

\begin{tabular}{|c|c|c|c|c|c|c|}
\hline \multirow[t]{2}{*}{ Group... } & \multicolumn{2}{|c|}{ Water $(n 6)$} & \multicolumn{2}{|c|}{ Milk (n 6) } & \multicolumn{2}{|c|}{$\begin{array}{l}\text { Active milk } \\
(n 6)\end{array}$} \\
\hline & Mean & SEM & Mean & SEM & Mean & SEM \\
\hline Kidney & $3 \cdot 11$ & 0.05 & $3 \cdot 11$ & 0.03 & 3.08 & 0.07 \\
\hline Heart & 3.40 & 0.05 & 3.57 & 0.07 & $3.66^{\star *}$ & 0.04 \\
\hline Left ventricle & $2 \cdot 83$ & 0.04 & 3.00 & 0.06 & $3.08^{\star *}$ & 0.04 \\
\hline Adrenal gland & 0.06 & 0.00 & $0.07^{*}$ & 0.00 & 0.07 & 0.00 \\
\hline
\end{tabular}

Mean value was significantly different from that of the group that received water ${ }^{\star} P<0.05,{ }^{\star \star} P<0.01$

with milk consumption and blood pressure has been demonstrated in several intervention studies in human subjects ${ }^{(10,47-49)}$. Although acute antihypertensive effects in SHR have been shown by several isolated or synthesised milk peptides ${ }^{(50-52)}$ and by different casein or whey hydrolysates $^{(53,54)}$, long-term intervention studies using pure milk or fermented milk are scarce. Miguel et al. ${ }^{(55)}$ reported that milk fermented by L. delbrueckii and Streptococcus thermophilus (without known antihypertensive peptides) attenuated the development of hypertension in SHR during an 8-week period slightly but significantly. In contrast, Sipola et al. ${ }^{(16)}$ did not observe any effect on SBP by a 14-week skimmed milk treatment. The fermentation process itself may partly explain why some of the fermented milk products decrease blood pressure, as it is possible that other, still unknown antihypertensive peptide sequences are cleaved from the milk protein during milk processing. Milk is rich in minerals (Ca, $\mathrm{K})$, which most probably also contribute to the antihypertensive effect. For example, the antihypertensive effect of $\mathrm{Ca}$ has been shown quite uniformly in $\mathrm{SHR}^{(25,56,57)}$.

Active milk significantly improved the endotheliumdependent relaxation of mesenteric arteries. Typically, from the age of 10 to 12 weeks, SHR show marked endothelial dysfunction $^{(58)}$. There seems to be no or little alteration in the production of NO. However, a marked attenuation in the EDHF-mediated component is observed in SHR resistant arteries, where endothelium-derived hyperpolarisations participate in endothelium-dependent relaxations ${ }^{(59-61)}$. Therefore, NO and possibly prostanoids to some extent are mostly responsible for the relaxation. This was seen also in the present study, as the relaxations were almost abolished after blocking COX and NOS. Nonetheless, the use of active milk improved the impaired EDHF-mediated responses. This has been observed also with antihypertensive drugs, most significantly with RAS inhibitors ${ }^{(62)}$. Thus, the beneficial effect of active milk on endothelial function was shown to be related to both NO and EDHF.

Both the active milk and milk increased the sensitivity of the mesenteric arteries to the endothelium-independent vasodilator SNP (although only the active milk significantly). In previous studies, fermented milk products containing tripeptides and plant sterols have not had any effect on SNPinduced vasorelaxation $^{(17,18)}$. In the present study the animals were older and thus arterial dysfunction may have been further progressed, so the positive effect of fermented milk products on smooth muscle function is more evident. Fermented milk products are high in L-cysteine ${ }^{(63)}$, which has been shown to augment endothelium-independent relaxation of isolated arteries ${ }^{(64)}$. Thus, the presence of L-cysteine in the active milk and milk could possibly explain the increased sensitivity of the mesenteric artery to SNP.

DNA microarray analysis showed that treatment with tripeptides and plant sterols produced only mild changes in aortic gene expression. There are not many studies describing dietinduced changes in aortic gene expression, but a few studies in which drugs have been used have been published ${ }^{(65,66)}$. In the present study, the ACE gene was slightly down-regulated, which is in line with previous findings considering the ACEinhibitory activity of the tripeptides ${ }^{(17,18,33,34)}$. Treatment with ACE-inhibitor drugs has also been shown to decrease ACE expression in $\mathrm{SHR}^{(67,68)}$.

Yamaguchi et al. ${ }^{(69)}$ investigated the effects of tripeptides on aortic gene expression by giving pure tripeptides to SHR for $5 \mathrm{~d}$. Changes in gene expression were not large in this study either, but significant up-regulation of eNOS and connexin40 genes were detected. We observed quite opposite effects, as both these two genes were rather down- than up-regulated in the present study. However, there may be distinct differences in gene expression profiles as regards short- and long-term treatment ( $5 \mathrm{~d} v$. 6 weeks). In some studies, the up-regulation of aortic eNOS has been associated with the improvement of endothelial function ${ }^{(70)}$ and reduction of blood pressure in $\mathrm{SHR}^{(71)}$. However, there are also studies where no changes in eNOS expression have been detected despite improved endothelial function ${ }^{(72)}$. Also, it must be taken into account that there are a considerable number of differences in gene expression profiles between SHR from different sources, not to speak of other models of experimental hypertension ${ }^{(73)}$. As in the present study the active milk treatment affected the NO-dependent relaxation slightly but significantly, it is possible that it either improved NO bioavailability or increased eNOS activity instead of directly affecting eNOS gene expression.

Although treatment with the active milk did not cause many changes in the gene expression, it clearly lowered blood pressure of the rats and improved endothelial function. It may be that several smaller changes cause the beneficial effects observed with tripeptides if they occur in parallel. The affected signalling pathways involved down-regulation of several genes that are linked to inflammatory processes (chemokine receptor, cell adhesion molecules, IL receptor). This is interesting, as the importance of chronic, low-grade inflammation in the pathogenesis of hypertension and vascular diseases has been recently acknowledged ${ }^{(74)}$. Long-term treatment with an ACE inhibitor captopril has been shown to decrease and increase the gene expression of pro- and anti-inflammatory cytokines, respectively, in SHR left ventricles along with blood pressure reduction as well ${ }^{(68)}$. The role of tripeptides in vascular inflammation has not been studied before and perhaps also deserves further attention.

As was observed in a kinetic study with normotensive Sprague-Dawley rats ${ }^{(75)}$, tripeptides seem to accumulate in tissues (for example, aorta, kidney). Therefore, it has been 
suggested that the local RAS would perhaps be more important as regards the antihypertensive and vasoprotective effects of tripeptides, especially as tripeptides have short plasma halflives $^{(76)}$. Although we were able to obtain tissue samples and thus reach the components of the local RAS in the present study, the effects of the active milk treatment on the expression levels of genes linked to the RAS and vascular function were mild. It may be that more changes in the gene expression levels would have been observed by using some other organ, for example, the kidney. In addition to tripeptides, the active milk also contained plant sterols, which may have influenced the gene profile. In the study of Chen et $a l^{(46)}$, 5 weeks of plant sterol or stanol treatment elevated mRNA levels of neuronal NOS or ACE1 and eNOS, respectively, in the kidney of stroke-prone SHR. This suggests that tripeptides and plant sterols may have partly opposing actions and that, despite clear antihypertensive and vasoprotective effects observed with the active milk in the present study, changes in the genes regulating these effects were not large enough to be detected in the analyses.

In conclusion, we describe for the first time that long-term intervention with a fermented milk product enriched with bioactive tripeptides and plant sterols can decrease already established, severe hypertension in addition to the prevention of the development of experimental hypertension. Whether this is related to improved endothelial function and vasodilatation remains open.

\section{Acknowledgements}

The study was carried out within the Valio Ltd Milk Protein Project funded by the Finnish Funding Agency for Technology and Innovation (Tekes).

Elina Lausvaara (Valio Ltd) is thanked for the preparation of the study products, Outi Monni's group (Institute of Biomedicine, Medical Biochemistry and Developmental Biology, Genome-Scale Biology Research Program, University of Helsinki) for the microarray work and Lilli Saarinen (Computational Systems Biology Laboratory, Institute of Biomedicine and Genome-Scale Biology Research Program, University of Helsinki) for the microarray data analysis.

The authors' responsibilities were as follows: all authors contributed to the planning, design and decision making of the study; P. I. E. and A. S. K. conducted the research; P. I. E. analysed the data and wrote the manuscript; P. I. E. and $\mathrm{H}$. V. had primary responsibility for the final content. All authors read and approved the final manuscript.

As regards conflicts of interest, A. M. T. is an employee of the Finnish dairy company, Valio Ltd. There are no other conflicts of interest.

\section{References}

1. Pereira M, Lunet N, Azevedo A, et al. (2009) Differences in prevalence, awareness, treatment and control of hypertension between developing and developed countries. J Hypertens 27, 963-975.
2. Kearney PM, Whelton M, Reynolds K, et al. (2005) Global burden of hypertension. Lancet 365, 217-223.

3. Mensink RP, Aro A, Den Hond E, et al. (2003) PASSCLAIM diet-related cardiovascular disease. Eur J Nutr 42, Suppl. 1, 6-27.

4. Krousel-Wood MA, Muntner P, He J, et al. (2004) Primary prevention of essential hypertension. Med Clin North Am 88, 223-238.

5. Katan MB, Grundy SM, Jones P, Stresa Workshop Participants, et al. (2003) Efficacy and safety of plant stanols and sterols in the management of blood cholesterol levels. Mayo Clin Proc 78, 965-978.

6. AbuMweis SS, Barake R \& Jones PJH (2008) Plant sterols/ stanols as cholesterol lowering agents: a meta-analysis of randomized controlled trials. Food Nutr Res 52 (epublication 18 August 2008).

7. Tapola NS, Lyyra ML, Karvonen HM, et al. (2004) The effect of meat products enriched with plant sterols and minerals on serum lipids and blood pressure. Int J Food Sci Nutr $\mathbf{5 5}$, 389-397.

8. Hallikainen M, Lyyra-Laitinen T, Laitinen T, et al. (2006) Endothelial function in hypercholesterolemic subjects: effects of plant stanol and sterol esters. Atherosclerosis $\mathbf{1 8 8}$ 425-432.

9. McCarron DA, Morris CD, Henry HJ, et al. (1984) Blood pressure and nutrient intake in the United States. Science 224, 1392-1398.

10. Appel LJ, Moore TJ, Obarzanek E, et al. (1997) A clinical trial of the effects of dietary patterns on blood pressure. DASH Collaborative Research Group. $N$ Engl J Med 336 1117-1124.

11. Toledo E, Delgado-Rodríguez M, Estruch R, et al. (2009) Low-fat dairy products and blood pressure: follow-up of 2290 older persons at high cardiovascular risk participating in the PREDIMED study. Br J Nutr 101, 59-67.

12. Korhonen H (2009) Milk-derived bioactive peptides: from science to applications. J Functional Foods 1, 177-187.

13. Pripp $\mathrm{AH}$ (2008) Effect of peptides derived from food proteins on blood pressure: a meta-analysis of randomized controlled trials. Food Nutr Res $\mathbf{5 2}$ (epublication 18 January 2008).

14. Xu JY, Qin LQ, Wang PY, et al. (2008) Effect of milk tripeptides on blood pressure: a meta-analysis of randomized controlled trials. Nutrition 24, 933-940.

15. Nakamura Y, Yamamoto N, Sakai K, et al. (1995) Antihypertensive effect of sour milk and peptides isolated from it that are inhibitors to angiotensin I-converting enzyme. J Dairy Sci 78, 1253-1257.

16. Sipola M, Finckenberg P, Korpela R, et al. (2002) Effect of long-term intake of milk products on blood pressure in hypertensive rats. J Dairy Res 69, 103-111.

17. Jäkälä P, Pere E, Lehtinen R, et al. (2009) Cardiovascular activity of milk casein-derived tripeptides and plant sterols in spontaneously hypertensive rats. J Physiol Pharmacol 60, 11-20.

18. Jäkälä P, Hakala A, Turpeinen AM, et al. (2009) Caseinderived bioactive tripeptides Ile-Pro-Pro and Val-Pro-Pro attenuate the development of hypertension and improve endothelial function in salt-loaded Goto-Kakizaki rats. J Functional Foods 1, 366-374.

19. Jauhiainen T, Pilvi T, Cheng ZJ, et al. (2010) Milk products containing bioactive tripeptides have an antihypertensive effect in double transgenic rats (dTGR) harbouring human renin and human angiotensinogen genes. J Nutr Metab 2010, 287030. 
20. Jauhiainen T, Collin M, Narva M, et al. (2005) Effect of longterm intake of milk peptides and minerals on blood pressure and arterial function in spontaneously hypertensive rats. Milk Sci Int 60, 358-362.

21. Jäkälä P, Turpeinen AM, Rajakari K, et al. (2010) Biological effects of casein-derived tripeptide powders are not affected by fermentation process. Int Dairy J 20, 366-370.

22. Masuda O, Nakamura Y \& Takano T (1996) Antihypertensive peptides are present in aorta after oral administration of sour milk containing these peptides to spontaneously hypertensive rats. J Nutr 126, 3063-3068.

23. Ghiadoni L, Bruno RM, Stea F, et al. (2009) Central blood pressure, arterial stiffness, and wave reflection: new targets of treatment in essential hypertension. Curr Hypertens Rep 11, 190-196.

24. Taddei S, Virdis A, Ghiadoni L, et al. (2000) Endothelial dysfunction in hypertension. J Nephrol 23, 205-210.

25. Mäkynen H, Kähönen M, Arvola P, et al. (1995) Dietary calcium and magnesium supplements in spontaneously hypertensive rats and isolated arterial reactivity. $\mathrm{Br} J$ Pharmacol 115, 1455-1462.

26. Sipola M, Finckenberg P, Vapaatalo H, et al. (2002) $\alpha$-Lactorphin and $\beta$-lactorphin improve arterial function in spontaneously hypertensive rats. Life Sci 71, 1245-1253.

27. Bagnost T, Berthelot A, Bouhaddi M, et al. (2008) Treatment with the arginase inhibitor $N \omega$-hydroxy-nor-L-arginine improves vascular function and lowers blood pressure in adult spontaneously hypertensive rat. $J$ Hypertens $\mathbf{2 6}$, 1110-1118.

28. Dal-Ros S, Bronner C, Schott C, et al. (2009) Angiotensin II-induced hypertension is associated with a selective inhibition of endothelium-derived hyperpolarizing factormediated responses in the rat mesenteric artery. J Pharmacol Exp Ther 328, 478-486.

29. Kane MO, Etienne-Selloum N, Madeira SV, et al. (2010) Endothelium-derived contracting factors mediate the Ang II-induced endothelial dysfunction in the rat aorta: preventive effect of red wine polyphenols. Pflügers Arch 459, 671-679

30. Mervaala EM, Cheng ZJ, Tikkanen I, et al. (2001) Endothelial dysfunction and xanthine oxidoreductase activity in rats with human renin and angiotensinogen genes. Hypertension 37, $414-418$.

31. Cheng ZJ, Vaskonen T, Tikkanen I, et al. (2001) Endothelial dysfunction and salt-sensitive hypertension in spontaneously diabetic Goto-Kakizaki rats. Hypertension 37, 433-439.

32. Jäkälä P, Jauhiainen T, Korpela R, et al. (2009) Milk proteinderived bioactive tripeptides Ile-Pro-Pro and Val-Pro-Pro protect endothelial function in vitro in hypertensive rats. J Functional Foods 1, 266-273.

33. Nakamura Y, Yamamoto N, Sakai K, et al. (1995) Purification and characterization of angiotensin I-converting enzyme inhibitors from sour milk. J Dairy Sci 78, 777-783.

34. Lehtinen R, Jauhiainen T, Kankuri E, et al. (2010) Effects of milk casein-derived tripeptides Ile-Pro-Pro, Val-Pro-Pro and Leu-Pro-Pro on enzymes processing vasoactive precursors in vitro. Arzneim Forsch/DrugRes 60, 182-185.

35. Jauhiainen T, Vapaatalo H, Poussa T, et al. (2005) Lactobacillus helveticus fermented milk lowers blood pressure in hypertensive subjects in 24-h ambulatory blood pressure measurement. Am J Hypertens 18, 1600-1605.

36. Engberink MF, Schouten EG, Kok FJ, et al. (2008) Lactotripeptides show no effect on human blood pressure. Results from a double-blind randomized controlled trial. Hypertension 51, 399-405.
37. Usinger L, Ibsen $\mathrm{H}$, Linneberg A, et al. (2010) Human in vivo study of the renin-angiotensin-aldosterone system and the sympathetic activity after 8 weeks daily intake of fermented milk. Clin Physiol Funct Imaging 30, 162-168.

38. Grundy SM, Cleeman JI, Merz CN, et al. (2004) Implications of recent clinical trials for the National Cholesterol Education Program Adult Treatment Panel III Guidelines. I Am Coll Cardiol 44, 720-732.

39. Laakso P (2005) Analysis of sterols from various food matrices. Eur I Lipid Sci Technol 107, 402-410.

40. Ovaska K, Laakso M, Haapa-Paananen S, et al. (2010) Largescale data integration framework provides a comprehensive view on glioblastoma multiforme. Genome Med 2, 65.

41. Irizarry RA, Bolstad BM, Collin F, et al. (2003) Summaries of Affymetrix GeneChip probe level data. Nucleic Acids Res 31, e15.

42. Benjamini Y \& Hochberg Y (1995) Controlling the false discovery rate: a practical and powerful approach to multiple testing. J R Stat SOC B 57, 289-300.

43. Tarca AL, Draghici S, Khatri P, et al. (2009) A novel signaling pathway analysis impact analysis. Bioinformatics 25, 75-82.

44. Kanehisa M, Goto S, Furumichi M, et al. (2010) KEGG for representation and analysis of molecular networks involving diseases and drugs. Nucleic Acids Res 38, D355-D360.

45. Nakamura Y, Masuda O \& Takano T (1996) Decrease of tissue angiotensin I-converting enzyme activity upon feeding sour milk in spontaneously hypertensive rats. Biosci Biotech Biochem 60, 488-489.

46. Chen Q, Gruber H, Swist E, et al. (2009) Influence of dietary phytosterols and phytostanols on diastolic blood pressure and the expression of blood pressure regulatory genes in SHRSP and WKY inbred rats. Br J Nutr 102, 93-101.

47. Hilary Green J, Richards JK \& Bunning RL (2000) Blood pressure responses to high-calcium skim milk and potassium-enriched high-calcium skim milk. J Hypertens 18, 1331-1339.

48. Buonopane GJ, Kilara A, Smith JS, et al. (1992) Effect of skim milk supplementation on blood cholesterol concentration, blood pressure, and triglycerides in a free-living human population. J Am Coll Nutr 11, 56-67.

49. Van Beresteijn EC, Van Schaik M \& Schaafsma G (1990) Milk: does it affect blood pressure? A controlled intervention study. J Intern Med 228, 477-482.

50. Nurminen ML, Sipola M, Kaarto H, et al. (2000) $\alpha$-Lactorphin lowers blood pressure measured by radiotelemetry in normotensive and spontaneously hypertensive rats. Life Sci 66, $1535-1543$

51. Miguel M, Recio I, Ramos M, et al. (2006) Antihypertensive effect of peptides obtained from Enterococcus faecalisfermented milk in rats. J Dairy Sci 89, 3352-3359.

52. Miguel M, Gómez-Ruiz JÁ, Recio I, et al. (2010) Changes in arterial blood pressure after single oral administration of milk-casein-derived peptides in spontaneously hypertensive rats. Mol Nutr Food Res 54, 1422-1427.

53. Costa EL, Almeida AR, Netto FM, et al. (2005) Effect of intraperitoneally administered hydrolyzed whey protein on blood pressure and renal sodium handling in awake spontaneously hypertensive rats. Braz J Med Biol Res 38, 1817-1824.

54. Geerlings A, Villar IC, Hidalgo Zarco F, et al. (2006) Identification and characterization of novel angiotensin-converting enzyme inhibitors obtained from goat milk. J Dairy Sci 89, $3326-3335$

55. Miguel M, Muguerza B, Sánchez E, et al. (2005) Changes in arterial blood pressure in hypertensive rats caused by 
long-term intake of milk fermented by Enterococcus faecalis CECT 5728. Br J Nutr 94, 36-43.

56. Pörsti I, Arvola P, Wuorela H, et al. (1992) High calcium diet augments vascular potassium relaxation in hypertensive rats. Hypertension 19, 85-92.

57. Tolvanen JP, Mäkynen H, Wu X, et al. (1998) Effects of calcium and potassium supplements on arterial tone in vitro in spontaneously hypertensive rats. Br J Pharmacol 124, 119-128.

58. Bernatova I, Conde MV, Kopincova J, et al. (2009) Endothelial dysfunction in spontaneously hypertensive rats: focus on methodological aspects. J Hypertens 27, Suppl. 6, S27-S31.

59. Onaka U, Fujii K, Abe I, et al. (1998) Antihypertensive treatment improves endothelium-dependent hyperpolarization in the mesenteric artery of spontaneously hypertensive rats. Circulation 98, 175-182.

60. Büssemaker E, Popp R, Fissthaler B, et al. (2003) Aged spontaneously hypertensive rats exhibit a selective loss of EDHFmediated relaxation in the renal artery. Hypertension $\mathbf{4 2}$, $562-568$.

61. Michel FS, Man GS, Man RY, et al. (2008) Hypertension and the absence of EDHF-mediated responses favour endothelium-dependent contractions in renal arteries of the rat. Br J Pharmacol 155, 217-226.

62. Goto K, Fujii K, Kansui Y, et al. (2004) Changes in endothelium-derived hyperpolarizing factor in hypertension and ageing: response to chronic treatment with renin-angiotensin system inhibitors. Clin Exp Pharmacol Physiol 31, 650-655.

63. Chandan RC (2006) Milk composition, physical and processing characteristics. In Manufacturing Yogurt and Fermented Milks, pp. 17-40 [RC Chandan, editor]. Oxford: Blackwell Publishing.

64. Arvola P, Pörsti I, Vuorinen P, et al. (1992) L-Cysteine augments the vasorelaxation induced by sodium nitrite and SIN-1 but not that due to acetylcholine. Eur J Pharmacol 214, 289-292.

65. Wang EQ, Lee WI, Brazeau D, et al. (2002) cDNA microarray analysis of vascular gene expression after nitric oxide donor infusions in rats: implications for nitrate tolerance mechanisms. AAPS Pharm Sci 4, E10.
66. Abd Alla J, Langer A, Elzahwy SS, et al. (2010) Angiotensinconverting enzyme inhibition down-regulates the proatherogenic chemokine receptor 9 (CCR9)-chemokine ligand 25 (CCL25) axis. J Biol Chem 285, 23496-23505.

67. Linz W, Jessen T, Becker RH, et al. (1997) Long-term ACE inhibition doubles lifespan of hypertensive rats. Circulation 96, 3164-3172.

68. Miguel-Carrasco JL, Zambrano S, Blanca AJ, et al. (2010) Captopril reduces cardiac inflammatory markers in spontaneously hypertensive rats by inactivation of NF-кB. J Inflamm (Lond) 7, 21.

69. Yamaguchi N, Kawaguchi K \& Yamamoto N (2009) Study of the mechanism of antihypertensive peptides VPP and IPP in spontaneously hypertensive rats by DNA microarray analysis. Eur J Pharmacol 620, 71-77.

70. Rodriguez-Rodriguez R, Herrera MD, de Sotomayor MA, et al. (2007) Pomace olive oil improves endothelial function in spontaneously hypertensive rats by increasing endothelial nitric oxide synthase expression. Am J Hypertens 20, 728-734.

71. Li H, Witte K, August M, et al. (2006) Reversal of endothelial nitric oxide synthase uncoupling and up-regulation of endothelial nitric oxide synthase expression lowers blood pressure in hypertensive rats. J Am Coll Cardiol 47, 2536-2544.

72. Rush JW, Quadrilatero J, Levy AS, et al. (2007) Chronic resveratrol enhances endothelium-dependent relaxation but does not alter eNOS levels in aorta of spontaneously hypertensive rats. Exp Biol Med (Maywood) 232, 814-822.

73. Okuda T, Sumiya T, Iwai N, et al. (2002) Difference of gene expression profiles in spontaneous hypertensive rats and Wistar-Kyoto rats from two sources. Biochem Biophys Res Commun 296, 537-543.

74. Marchesi C, Paradis P \& Schiffrin EL (2008) Role of the renin-angiotensin system in vascular inflammation. Trends Pharmacol Sci 29, 367-374.

75. Jauhiainen T, Wuolle K, Vapaatalo H, et al. (2007) Oral absorption, tissue distribution and excretion of a radiolabelled analog of a milk-derived antihypertensive peptide, Ile-Pro-Pro, in rats. Int Dairy J 17, 1216-1223.

76. Foltz M, Meynen EE, Bianco V, et al. (2007) Angiotensinconverting enzyme inhibitory peptides from a lactotripeptide-enriched milk beverage are absorbed intact into the circulation. J Nutr 137, 953-958. 